\title{
Fertility in Finland in the 1980s and 1990s: Analysis of Fertility Trend by Age and Parity
}

\author{
ANDRES VIKAT, Ph.D. \\ Research Scientist \\ Max Planck Institute for Demographic Research, Rostock, Germany
}

\begin{abstract}
The purpose of this article is to describe the fertility trend in Finland from 1982 to 1999 by age and parity, using age- and parity-specific birth intensities and synthetic cohort measures of period fertility. The findings are discussed in the light of the concurrent changes in family policy and macroeconomic environment, and in the context of fertility developments in other Nordic countries. From 1982 to 1987, first-birth rates decreased while second and higher order birth rates changed little. From 1987, there was a rise in women's fertility at all parities throughout the reproductive age span. In first births, this increase reverted to a decrease in 1991. Second and higher order birth rates continued to increase until 1994. Third and higher order births have somewhat decreased thereafter. First-birth rates of women over 35 have risen throughout the study period, and the mean age at first birth has increased.
\end{abstract}

Keywords: fertility, birth order, intensity regression, parity, parity progression, Finland

\section{Introduction}

In the last two decades of the $20^{\text {th }}$ century, the level of period fertility in Finland has been relatively stable when compared to the 1960s and 1970s. A decrease in fertility started in the 1950s, and a spectacularly large drop occurred from the mid1960 s to the mid-1970s. Since 1974 , the total period fertility rate has fluctuated between 1.6 and 1.8, and for the last 25 years as a whole, there is no systematic tendency toward an increase or decrease. This pattern of fertility trend over the last 35 years - a rapid and sizable decline followed by a period of smaller fluctuations - 
is shared by most other West and North European countries, and has received much attention from demographers. This has been accompanied by an increase in the mean age at childbearing, another trend that has been observed in most West and North European countries for more than 30 years. Together with the parallel changes in family dynamics, contraception, and value orientations, the fertility decline is interpreted as one of the manifestations of the second demographic transition, an empirical generalization frequently used as a general framework for studies on fertility and family dynamics from the 1960s onward (Lesthaeghe 1995).

The period of the onset of fertility decline in the 1960s and its subsequent leveling off in Finland has been analyzed from both period and cohort perspectives (Finnäs 1988; Notkola 1994; 1995), and there has been one recent study on cohort fertility that also covers the 1990s (Frejka and Calot 2001). The time range of the latest studies of period fertility ends with the year 1990, and thus the dynamics of about ten years has not been subjected to analysis beyond routinely published statistics. The explanations that applied to the fertility decline in the 1960s and 1970s - with increased effectiveness of contraception and access to abortion in the forefront are no longer applicable in explaining the period patterns. Childbearing decisions are made under circumstances where everybody can access effective contraception, and the welfare state has made it easier than before to combine childbearing with employment. Entry into parenthood is usually postponed until the completion of education and starting a working career, and social and family policies further motivate such a pattern.

In the European context, the Nordic countries are all in the same cluster on the basis of the principles of organization of the welfare state (Esping-Andersen 1990), on the basis of the applied social and family policies (Wennemo 1994), and because they also share the main features in fertility and family dynamics. Current fertility levels in the Nordic countries are relatively high in the European context (Council of Europe 2000), and the policies aiming at reconciliation of family and work can be viewed as contributing to this. In several instances new policy measures or improvement of existing measures has been seen as a driving force behind an increase in period fertility: in Sweden in the second half of the 1980s, as a response to the new family policy measure that introduced the speed premium (Hoem 1993b), in Denmark from the mid-1980s to the mid-1990s (Knudsen 1999), and in Finland and Norway in the end of the 1980s (Ilmakunnas 1994; Rønsen 1998).

In Northern and Western Europe the changes in period fertility levels were typically not major in the 1980s and 1990s, at least when compared to the change during the 1960s and 1970s, but they could still be subject to volatile reactions to social policy measures or economic cycles, as has been shown in the case of Sweden (Hoem 1993b; Andersson 2000). In Finland, the period total fertility rate was at a high point of 1.74 in 1983, then decreased to 1.59 in 1987, increased to 1.85 in 1992 
and 1994, and reached another local low point of 1.70 in 1998 (Council of Europe 2000). These fluctuations of the total fertility rate are smaller than in Sweden and Denmark during the same period, and about the same as in Norway (Figure 1).

Figure 1. Total fertility rate in Finland, Denmark, Norway and Sweden, 1960-1999 (Source: Council of Europe 2000).

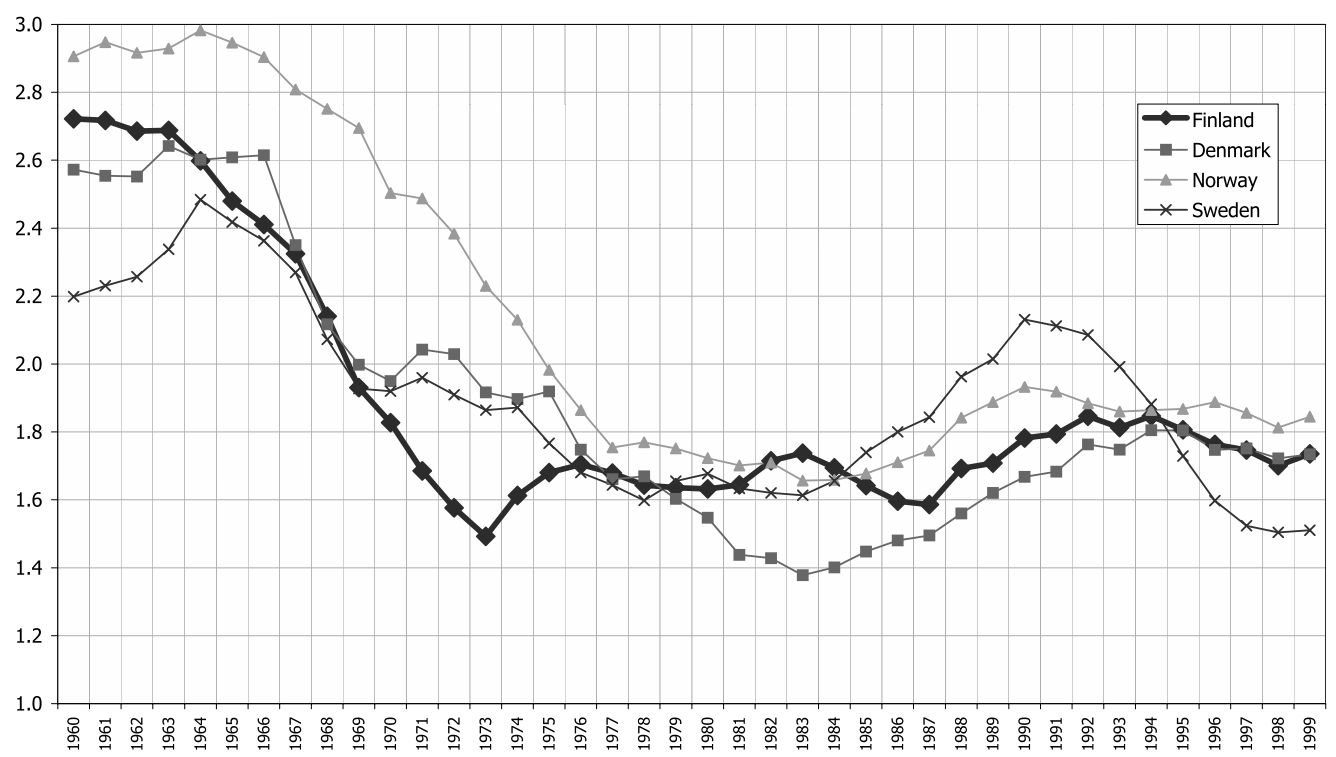

The period total fertility rate that was used in the comparison above is the most widely used measure of the level of period fertility, and its deficiencies are well known. The two probably most widely discussed properties are that the total fertility rate does not consider the sequencing of births of different order, in other words, the parity structure of the population, and that it underestimates the fertility level under the circumstances of postponement of childbearing (and correspondingly overestimates it at periods when childbearing is shifting to younger age). In this article, the first aspect will receive direct attention. When the focus is on analyzing temporal change in fertility in relation to the concurrent developments in society, the factors that emerge from demographic structure need to be considered as far as possible, and adjustment by parity that is used in this article is one step in this. It also has to be considered that women's fertility at different parities may respond differently to changes in the macroeconomic environment or social policies, and this may remain masked if parity-specific measures are not available.

The purpose of this article is to describe the fertility trend in Finland from 1982 to 1999 by age and parity. For this period, a comparable set of age- and parity-specific period fertility measures could be constructed. The findings are discussed in light of the concurrent changes in family policy and macroeconomic environment, and in the context of fertility developments in other Nordic countries. 


\section{Data and Methods}

The data was obtained from Statistics Finland in the form of annual numbers of births and female population at the end of a year by single years of age and parity for the period 1982 to 1999. For 1982 and 1983, population data was available by age and not by parity. For these years, the parity distribution at each single age was estimated using the parity distributions at the end of 1981 and 1984, and the number of births by age and parity in 1982 and 1983.

As the first step in the analysis, age- and parity-specific fertility rates by singleyear age group were calculated, using the mid-year population of corresponding age and parity as the estimate for the exposure. The term intensity is used to refer to these occurrence-exposure rates throughout this article, to facilitate the distinction between them and the fertility rates by birth order, where the population in the denominator includes women of respective age regardless of parity. Agestandardized annual indices for broader age groups were computed by fitting a hazard regression model with age and calendar year as covariates (Hoem 1993a), using GLIM software (Aitkin et al. 1989). These obtained indices express agestandardized birth intensity relative to a certain year of reference.

In addition, fertility is described from the synthetic cohort perspective. To this end, a hierarchical multistate life table was calculated on the basis of the observed ageand parity-specific fertility intensities. This life table characterizes the life course of a synthetic cohort of childless women at age 15 who would experience the ageand parity-specific fertility of a given calendar year until they reach age 50 . The life table population $l$ at age $x$ and parity $i$ is determined by the probability to remain at parity $i$ at age $x-1$, and the probability of $i^{\text {th }}$ birth at age $x-1$ (formulas 1-3 are adapted from Rallu and Toulemon 1994, pp. 65-67, and formula 4 from Feeney et al. 1989, pp. 308):

for $x \geq 16, i=0$

$$
l_{x .0}=l_{15 . n} \prod_{15 s, j<x}\left(1-q_{j, 1}\right)
$$

for $x \geq 16, i \geq 1$

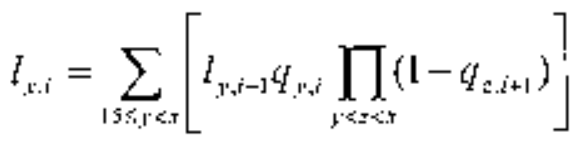

where $q_{x, i}$ is the probability to give birth to the $i^{\text {th }}$ child at age $x$. 
The parity distribution of such a synthetic cohort at age $50, l_{50, i}$ is treated as the final parity distribution, and from that the parity progression ratios $a_{i}$ from parity $i$ to $i+1$ and the total fertility index adjusted for parity and age (TF) are obtained.

$$
\begin{aligned}
& a_{i}=\frac{\sum_{j \geq 1>1} l_{50, j}}{\sum_{i \Sigma i} l_{S U, j}} \\
& \mathrm{TF}=\sum_{j=0}^{\pi} \prod_{j=0}^{j} a_{i}
\end{aligned}
$$

The empirical calculations were performed up to parity seven, since that information was available for the entire study period. A correction factor for eighth and higher order births was calculated in the form of the total fertility rate for eighth and higher order births (the values range from 0.01 to 0.03 ), and this was added to the total fertility index.

The period parity progression ratio expresses the proportion of women who experience $i+1^{\text {th }}$ birth in their lifetime from all women who reach parity $i$ if they were subjected to the age- and parity-specific fertility of a given calendar year throughout their reproductive lives. The total fertility index expresses the average number of children per woman if 15 -year-old childless women were subjected to the age- and parity-specific fertility of a given calendar year throughout their reproductive lives. It is thus based on the parity distribution that is created by the observed age- and parity-specific fertility itself, whereas the conventional total fertility rate and its birth order components do not consider any underlying parity distribution.

For the examples and details of earlier use of these indicators, the reader is referred to Feeney et al. (1989) and Rallu and Toulemon (1994). In addition, Park (1976) used this approach to present the lifetime probability of $i^{\text {th }}$ birth, and Kohler and Ortega (2001) used this type of indicators in further methodological developments. 


\section{Results}

\section{Entry into motherhood}

First-birth intensities by single-year age group reveal that the trend in the propensity to become a mother varies considerably depending on age. It is apparent from Figure 2 that the first-birth intensities at all single ages below 28 were lower in the 1990 s than in the 1980s. On the contrary, first-birth intensities at ages 30 and over increased during the observed period. Within the two age-ranges, the curves of single-year age-groups are fairly parallel. The crossover of age-specific first-birth intensities took place in the age range from 27 to 30 (Figure 2). Within this age range, the first-birth intensity declined with age at the beginning of the 1980s, and increased with age at the end of the 1990s. The intensity schedule of first births has thus shifted towards older age. 

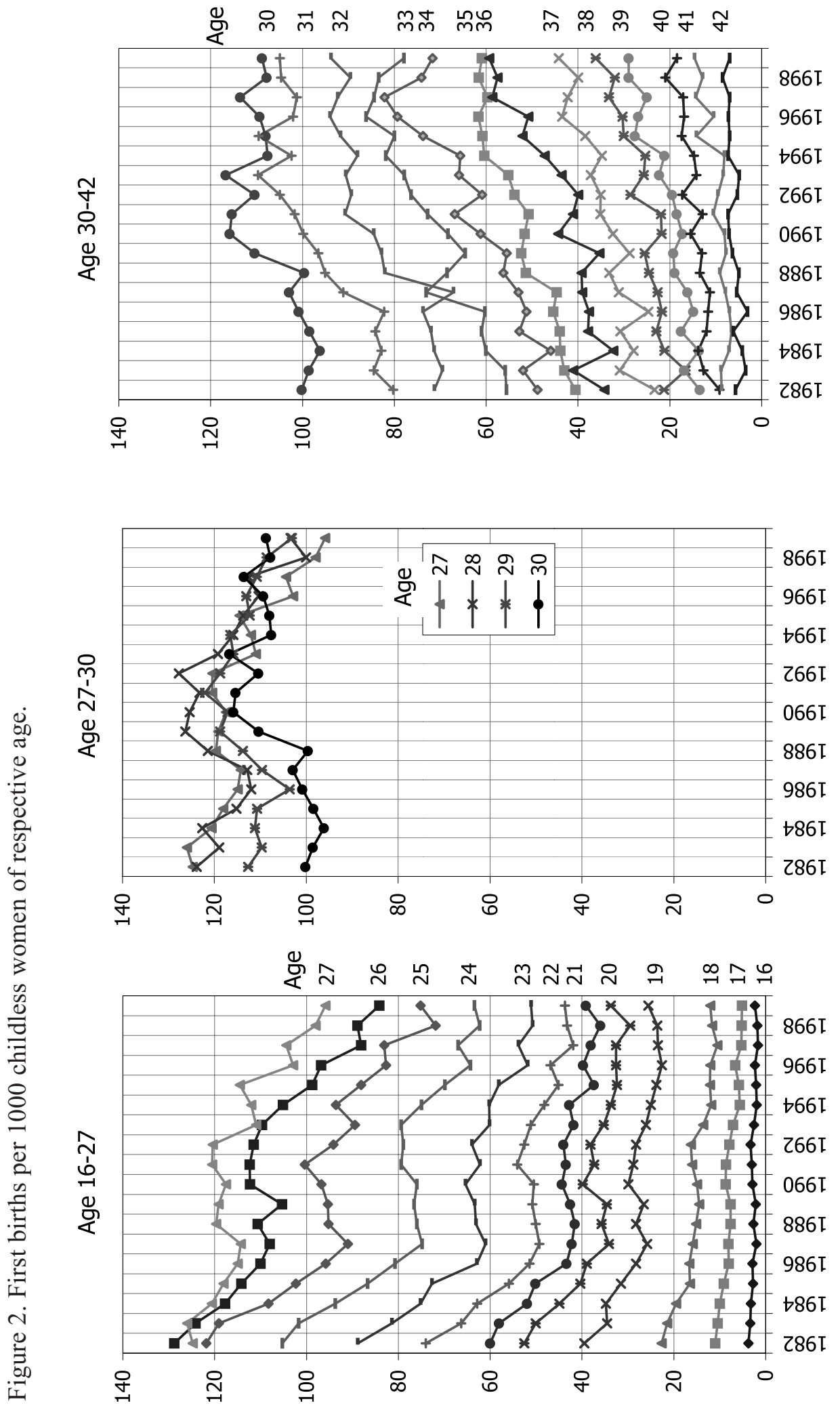
The above-described pattern can be summarized by the age-standardized annual index of first-birth intensities computed separately for the age groups where the main features of the trend over the study period were more or less homogeneous (Figure 3). There is an obvious contrast between the trend of women over age 30 and those below 28. However, from 1987 to 1991, the first-birth intensity of younger women was increasing, which was contrary to the general trend in this age group. After 1992, the first-birth intensity of younger women continued to decline. The first-birth intensity of women over 30 increased fairly modestly from 1982 to 1986 , by $5 \%$. In the following ten years, from 1986 to 1995, the increase amounted to $37 \%$. From 1995 onwards, there was only very little further increase in the first-birth intensity over age 30 as a whole. However, in order to describe the developments in the trend in the second half of the 1990s, the age group of 31-49 has to be split into two. This reveals that, among 31-35-year-olds, the trend turned downward after 1995, while in the over 35-year-olds the increase even accelerated. This development contrasts with the period up to 1995, when the trend of firstbirth intensity did not vary substantially among women aged over 30 .

Figure 3. Age-standardized annual index of first-birth intensities by age group.

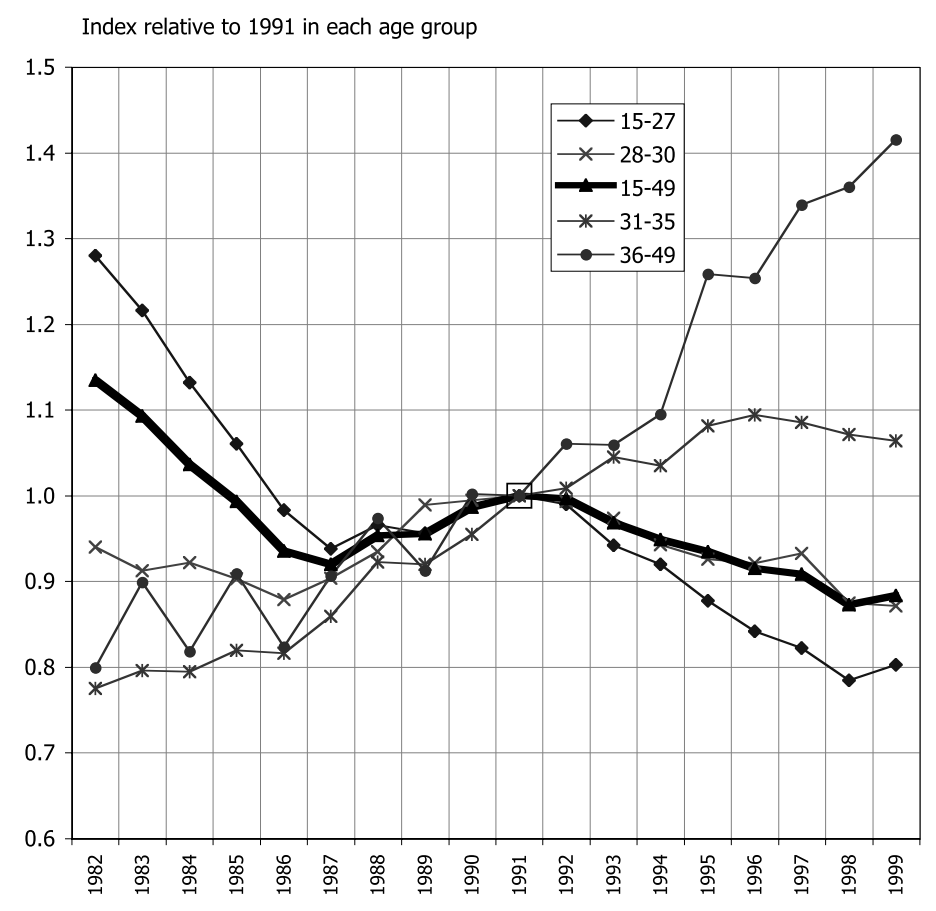


The indices plotted in Figure 3 indicate that in 1987 there was a period effect that influenced the propensity to become a mother toward increase at any age. In younger women this appeared as the reversal of the downward trend, but it is also reflected in the larger increase in the first-birth intensity of older women from 1987 to 1991. This is also the only period when the age-standardized index of first-birth intensity calculated for the entire reproductive age span increased.

The age differences of the trend in first-birth intensity reflect the postponement of entry into motherhood, as the intensity of younger women decreased and that of older women increased. The rapid increase in the first-birth intensity of women over 35 obviously reflects the further postponement of entry into motherhood, with the arena of this postponement increasingly shifting to ages over 30 .

The mean age at first birth describes the underlying process of postponement of first births in a compact manner. In Table 1 (see the Appendix) the mean age calculated by two different methods is presented. One is obtained from the life table that is based on first-birth intensities, and the other is based on age-specific firstbirth rates where the number of first births is related to the number of women of respective age regardless of parity (the latter is the one most often used in international comparisons). Both show a fairly similar pattern, though in the period from 1987 to 1991, there was no postponement according to the life table based mean age. Both indicators of mean age showed no further postponement in the most recent observed year, from 1998 to 1999.

The plateau of the life table mean age from 1987 to 1991 means that there was no change in the distribution of the intensities in those years. The conventional mean age increased in those years only because of structural reasons: the distribution of childless women had become older as a consequence of postponement of entry into motherhood in earlier periods, and this was also a reason why more first births per women at any parity were observed at a later age. 


\section{Second and higher order births}

The trend of second-birth intensity does not show as large a discrepancy by age as that of first-birth intensity. Nevertheless, the postponement of fertility is clearly reflected in the age-specific second-birth intensity, in the way that second-birth intensities of older women tended to increase over the study period more than those of younger women. As the analysis of first-birth intensities showed, first births were postponed to a later age throughout the study period. Consequently, at any age, the mothers of one child have on average younger children towards the end of the observation period. It can be assumed that there is an underlying pattern of proceeding to the next birth as a function of the age of youngest child, and the shift of the age at first birth would also shift this parity-progression schedule by age of youngest child to a later age of the mother. Usually, there is a desire to space children so that childrearing can feasibly be organized by the family, and for a number of other considerations. The average interval between the first and second birth in Finland has ranged around 3.6 years (Nikander 1992).

Like in the analysis of first-birth intensities, the second-birth intensities are summarized as a relative index in two age groups that were selected on the basis of the trend by single-year age group. From 1982 to 1992, second-birth intensities increased in both the younger (20-30) and the older group (31-49) of women at parity one (Figure 4). After 1992, the increase continued among those over 30, whereas the second-birth intensities of younger women at parity one turned toward a decrease. The age-standardized second-birth index for the whole reproductive age span increased modestly from 1982 to 1987, followed by a 27\% increase from 1987 to 1994, and a slight downward trend thereafter (Figure 5). 
Figure 4. Age-standardized annual index of second-birth intensities by age group.

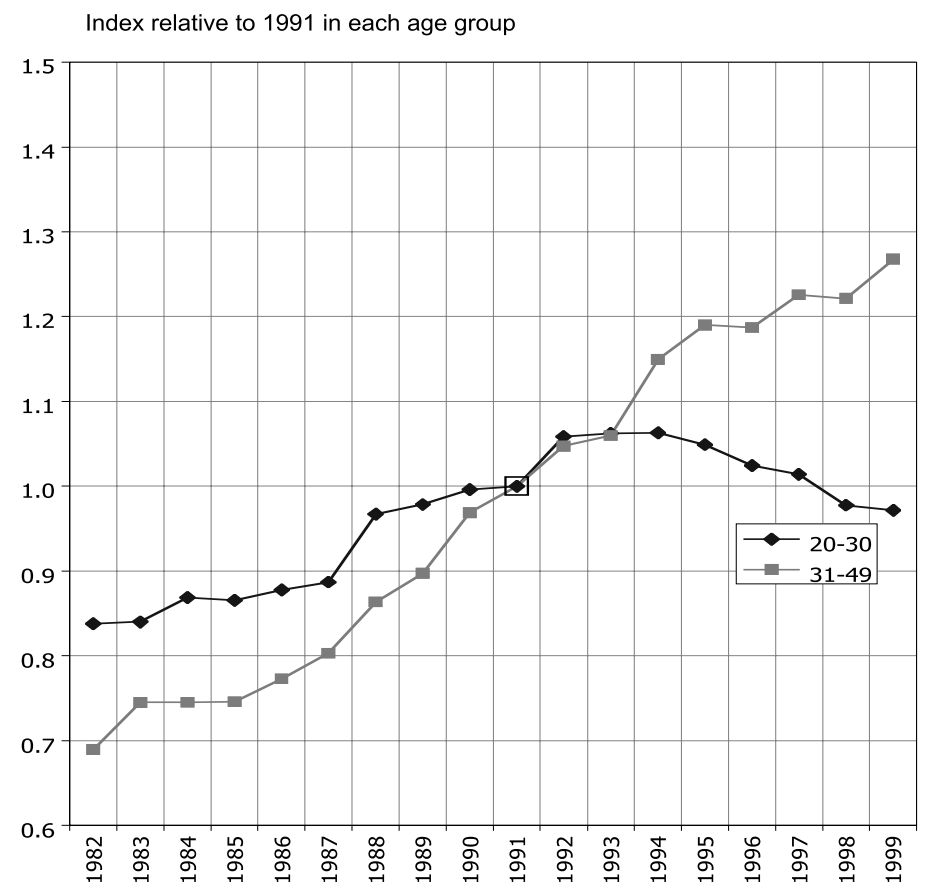

Figure 5. Age-standardized annual index of birth intensities by birth order.

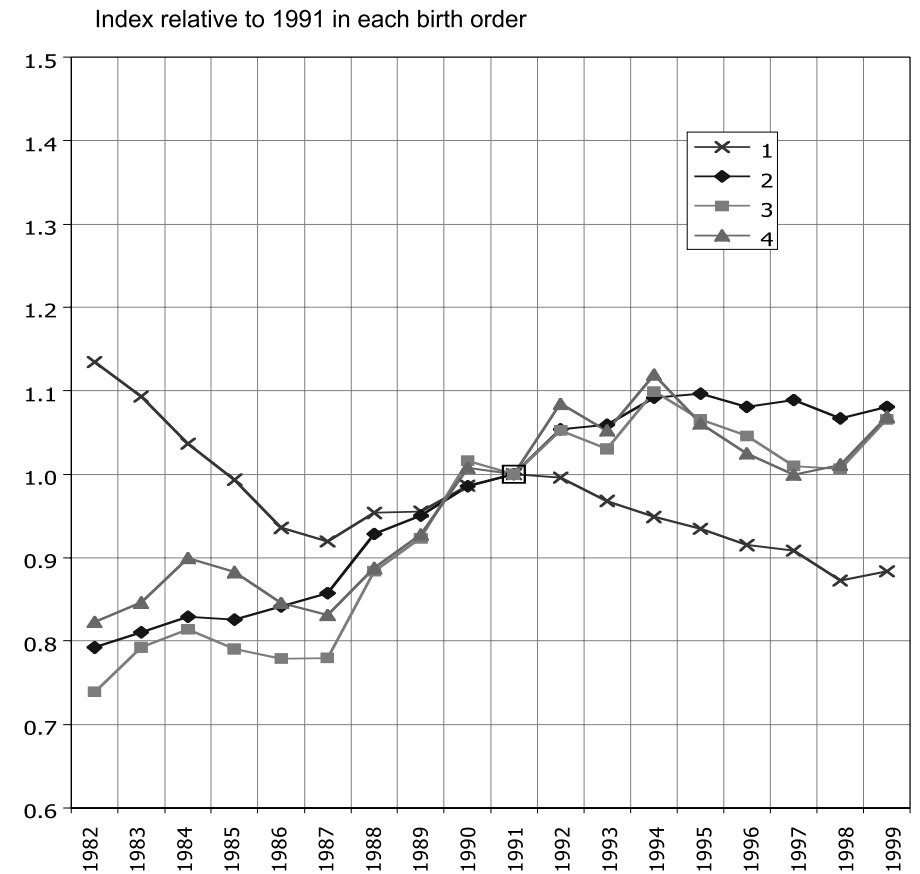


In Figure 5, the age-standardized annual indices of birth intensities by birth order are plotted relative to their 1991 level. The third- and fourth-birth intensities have changed over the observation period in roughly the same manner as those of second births, and the three periods distinguished in the second-birth trend are clearly discernible also in the trend of third and fourth births. The increase from 1987 to 1994 amounted to $41 \%$ in the index of third births and 35\% in the index of fourth births. As a difference from the trend in second births, the third- and fourth-birth indices showed somewhat more fluctuation in the mid-1980s and in the second half of the 1990s than the index of second-birth intensities.

\section{Parity progression ratios and total fertility}

In the following, the age- and parity-specific birth intensities are summarized from a synthetic cohort perspective, that is, describing the fertility of a cohort of 15 -year-old childless women who are subjected to the birth intensities observed in a calendar year. Parity progression ratio from zero to one child (lifetime probability of becoming a mother) decreased from 0.80 in 1982 to 0.76 in 1986 and 1987, then increased to 0.79 in 1991 and 1992, and has been slightly decreasing again to the level of 0.77 in the last two years measured (Appendix, Table 1). Although this is a better standardized measure than the first-birth component of the total fertility rate, it would not be appropriate to use this as a predictor of the final proportions of mothers and childless women in a real cohort. In view of the ongoing postponement, the parity progression ratios are subject to underestimation like any period measure of fertility, and at the same time it is difficult to predict how far the increase in the first-birth intensities of women in their late thirties and forties will go in the future.

According to the fertility level in the first half of the 1980 s, $70 \%$ of one-child mothers would go on to have a second child. By 1992 this progression ratio increased to the level of 0.75 and remained at around 0.74 in the second half of the 1990s. Progression ratios from two to three and from three to four children displayed somewhat more variation. When compared to parity progression ratio from one to two children, the higher parity progression ratios had more substantial drops from 1982 to 1987 , and from 1994 to 1998 . According to the late 1990s level, 38\% of two-child mothers go on to have a third child, and $27 \%$ of those with three children would have a fourth child.

Differently from the relative indices by birth order, presented in previous sections, the population in the denominator of parity progression ratios from parity $i$ to $i+1$ depends on the birth intensities prior to parity $i$ observed in the same year. In the mid-1980s, there was a relatively rapid postponement of first births, and the population at parity one produced by these first-birth intensities became older accordingly. This may play a role in the decrease of parity progression ratios from 
parity one to two from 1982-1984 to 1985-1987. The second-birth intensities did not drop in the 1980s.

The cumulative outcome of the described parity progression ratios is the total fertility index (Appendix, Table 1). The direction of the trend and the turning points of the index are identical with that of the total fertility rate throughout the observed period, but the index is constantly at a lower level than the conventional total fertility rate by $0.05-0.10$ children per woman. The difference in the level of the two aggregate indicators stems from the difference between the actual parity structure of the population in a given year and the structure that emerges from the birth intensities of that year. As the postponement of first births has been going on for a long time, the conditions of any of the observed years would produce a higher proportion of childless women at each age than there were in the actual population. The exposure to higher order births in the synthetic cohorts starts at a later age compared to the actual population and the proportion of those who reach higher order births would be lower on the basis of the observed intensities. The difference between the levels of the total fertility rate and the parity adjusted total fertility index can be interpreted as the influence of the current parity structure of the population on total fertility: if current age- and parity-specific birth intensities would continue to prevail, the conventional total fertility rate would decrease for merely structural reasons.

In sum, the analysis of the fertility trend suggests that there are certain period factors that have influenced fertility. The year 1987 can universally be located for women at all parities throughout the reproductive age span as a turning point towards an increase. It was also found that the fertility increase came to an end in the 1990s, but there was no universal turning point that would apply across parity and age. The propensity of entry into motherhood among younger women returned to a decrease in 1992, while fertility of parous women continued to increase until 1994. After that year fertility at all parities somewhat decreased. Finally, fertility in 1999 was again slightly higher compared to 1998 in all birth orders, but since this is the last year observed in this analysis, it would be premature to consider this as another turning point in the trend.

\section{Discussion}

It has been on the surface throughout this article that there was an ongoing postponement of fertility in Finland, like in most European countries, in the 1980s and 1990s. All the period indicators of fertility, including the age- and parity-specific intensities used in this analysis, are influenced by this postponement. Recently, there have been a number of developments aimed to improve the existing measures of 
period fertility by considering the change in timing, which would mean postponement in the context of the developed world (Bongaarts and Feeney 1998, Kohler and Philipov 2001; Kohler and Ortega 2001). Kohler and Ortega (2001) have shown how the postponement and changes in the variation of fertility intensities can simultaneously be considered in producing fertility measures that adjust for the ongoing process of postponement. In their application on Swedish data, the adjusted and observed levels had the greatest difference in measures of first and second births. The difference usually correlated with the observed pace of postponement, and the location of crucial turning points in the trend was not affected by the adjustment. An explicit consideration of postponement in the calculation of period fertility measure would help to further disentangle the interplay of timing and level in the recent Finnish fertility trend.

The analysis in this article revealed certain turning points in the Finnish fertility trend in the 1980s and 1990s. In order to understand the driving forces behind the fertility trend, the next step is to analyze the interplay of childbearing with different social phenomena. One route to follow in mapping out possible explanations is to study the changes in social policies and labor market conditions over the same period: a change in the fertility level may be a response to a policy change or to a change in macroeconomic conditions and the related individual life prospects.

In the two last decades, the most important change in Finnish social policy in terms of families with children was the introduction of the child home-care allowance. In addition, it is also important to note that in 1982, at the beginning of the period analyzed in this study, a considerable increase in the amount and duration of the parenthood allowance was implemented. Its income compensation level went as high as $80 \%$, and was lower for the parts of income that exceeded certain limits. The total length of time the allowance was paid at that time was 258 working days (Social Insurance Institution 2000). During the studied period there were minor changes in the length of the period when parental allowance was paid, and on three occasions during 1992-1993 (the recession time), the level was somewhat reduced. The current level is a maximum of $70 \%$, with step-by-step decreases towards higher income brackets (Social Insurance Institution 2000).

The home-care allowance receives more attention here because it was an essentially new policy measure that was introduced in Finland during the observation period. The law on the home-care allowance was passed in 1985 and became fully effective in 1990. It was initiated to promote an alternative way of taking care of small children under three years of age at home in a context where the demand for public day-care services exceeded supply. Although the municipalities had to guarantee a public day-care slot for all those who wanted one by 1990, many municipalities exercised their autonomy by providing a local supplement to home-care allowance instead of expanding day-care services. The allowance itself consisted of a baseline 
part and a means-tested supplement. By the end of 1987, a quarter of all children under three were covered by home-care allowance; this figure increased to $42 \%$ in 1990 (Muuri and Vihma 1991), further to 52\% in 1993-1994, and remained around $45 \%$ thereafter (Social Insurance Institution 2000). In 1991, there was a $24 \%$ increase in the size of the allowance (the base amount increased from EUR 251 to 311 per month). In 1996, the allowance was again reduced to the pre-1991 level, while public day-care services have been considerably expanded since 1994.

Many authors (Ilmakunnas 1994; 1997, Sipilä 1995; Korpinen 1997; Sipilä and Korpinen 1998; Takala 2000) have discussed the ways in which this measure influenced the pattern of childrearing in Finnish families. Sipilä and Korpinen (1998) have emphasized the importance of this policy during the times of economic recession in the first half of the 1990s. Although the municipal supplements almost disappeared during the recession, the means-tested part of the allowance went up as earned incomes dropped. It is plausible that the home-care allowance created a situation where women could see the prospect of childbearing and childrearing as an attractive alternative in the context of their own unemployment or a threat of unemployment, and in the context of shrinking opportunities in the labor market. In this respect it is important that until 1993 it was possible to receive the homecare allowance also when unemployed. Beginning in 1995, it was no longer possible to simultaneously receive the home-care allowance and unemployment benefits in the same family.

The fertility trend, particularly that of second and higher order births, has parallel features with the increase and decrease in the numbers of families receiving the home-care allowance and the size of the allowance itself. The onset of the increase in fertility in 1987 took place when the use of the home-care allowance was gaining momentum, and second and higher order births continued to increase after the 1991 increase in the amount of the allowance. If the home-care allowance had an increasing effect on fertility, the observed fertility trend, particularly that of second and higher order births, would support this interpretation. This positive correlation on the aggregate level warrants a closer look at the association of this essentially new family policy measure with fertility. Comparison of aggregate time series would not help us further at this point, and a study using more detailed data is needed.

In the first half of the 1990s, Finland was struck by a heavy economic recession. Although the Finnish welfare state on the whole retained its Nordic standards (Heikkilä and Uusitalo 1997), there were marked changes in various spheres of life. Disposable incomes decreased as tax rates were increased; some benefits, including the parenthood allowance, were reduced, and eligibility requirements for housing support were tightened. Unemployment increased from 5\% in 1990 to 20\% in 1993, and was especially high among younger people (Statistics Finland 2001). The 
recession affected the well-being of families with children through various pathways (Forssén 1999).

Contrary to the classical theory of New Home Economics (Becker 1981), Andersson (2000) found that woman's income had a strong positive effect on entry into motherhood and a small effect on second and higher order births in Sweden. The general explanation for this relationship lies in the policies that enable reconciliation of family and working life and provide a high level of income-related compensation for childrearing time. The effect of a woman's unemployment on the propensity to give birth has varied in different studies, with a majority finding that those currently unemployed have a somewhat higher propensity to give birth (Kravdal 1994; Andersson 2000). On the other hand, male earnings may have a more clear-cut effect on the increase of fertility, and male unemployment would create the kind of uncertainty that may reduce the propensity to have a(nother) child. On the whole, the atmosphere of relative uncertainty created by an economic recession may have a depressing effect on fertility regardless of the family members' own experience of unemployment or decreasing incomes. The reduced opportunities to start a working career on a sound footing can certainly be assumed to have an effect on entry into parenthood, since the family formation pattern in the Nordic countries can be characterized by a desire to start childbearing in a situation when there is certain stability in partnership and working status from the family's perspective. Hoem (2000) has found an area-level association between an increase in unemployment and a decrease in fertility, and Andersson (2000) has shown that the fertility trend in Sweden in the 1980s and 1990s paralleled trends in the macroeconomic environment.

The Finnish fertility trend described in this article does not show a positive correlation with the economic cycle. At first glance, the case may even appear to be the opposite, as the highest levels of period total fertility since 1970 were recorded in 1992-1994, the years of the economic recession. The results on fertility by parity indicate, however, that the rise in the propensity of entry into motherhood that was under way from 1987 onwards came to an end exactly in 1991, the same year when the recession really hit, and reverted to a decrease in the following year. So if decreased opportunities in the labor market and decreased incomes had an effect towards decreasing the propensity of entry into motherhood, there is some support to this assumption from the changed direction of the first-birth trend. The upward trend of second and higher order births continued through the recession and turned to a slight decrease only in 1994. One may argue that this could represent a reaction to the lowering of the levels of several benefits in the recession years, but it would be necessary to analyze it against the background of the overall improvement of the macroeconomic climate that began in 1994-1995, and the slowly improving situation in the labor market. 
The ideas presented in this discussion aim at mapping out a field where possible explanations for the fertility development can be sought. The possibilities to address these issues directly are improving, as new data sets for fertility research are going to materialize from Statistics Finland. It would be essential to base such a study on both individual and macro-level data, and in view of the local differentials in the implementation of certain policies, possibly also at the municipality level. The mechanism of the ways in which the labor market and family policies are related to fertility at different life course stages is complex and needs further empirical investigation.

\section{Acknowledgement}

I wish to thank Statistics Finland for providing the data for the analysis.

\section{References}

Aitkin, M., D. Anderson, B. Francis and J. Hinde. 1989. Statistical modelling in GLIM. Oxford Statistical Science Series. Oxford University Press.

Andersson, G. 2000. The impact of labour-force participation on childbearing behaviour: Pro-cyclical fertility in Sweden during the 1980s and the 1990s. European Journal of Population 2000; 16 (4): 293-333.

Becker, G.S. 1981. A treatise on the family. Harvard University Press.

Bongaarts, J. and G. Feeney. 1998. On the quantum and tempo of fertility. Population and Development Review 24 (2): 271-291.

Council of Europe 2000. Recent demographic developments in Europe: 2000. Strasbourg: Council of Europe.

Esping-Andersen, G. 1990. The three Worlds of Welfare Capitalism. Princeton: Princeton University Press.

Feeney, G., F. Wang, M. Zhou and B. Xiao. 1989. Recent fertility dynamics in China: Results from the 1987 One Percent Population Survey. Population and Development Review 15 (2): 297-322.

Finnäs, F. 1988. The fertility trends among married Finnish women born 1932-58. Yearbook of Population Research in Finland 26 (1988): 26-36.

Forssén, K. 1999. Families with children in recessionary Finland. Yearbook of Population Research in Finland 35 (1998-1999): 145-157.

Frejka, T. and G. Calot. 2001. Cohort reproductive patterns in the Nordic countries. Demographic Research [online] 5 (5), available at $<$ http://www.demographic-research.org/Volumes/Vol5/5/5-5.pdf $>$

Heikkilä, M. and H. Uusitalo (editors). 1997. The cost of cuts. Studies on cutbacks in social security and their effects in the Finland of the 1990s. Helsinki: STAKES.

Hoem, B. 2000. Entry into motherhood in Sweden: The influence of economic factors on the rise and fall in fertility, 1986-1997. Demographic Research [online] 4 (2), available at $<$ http://www.demographic-research.org/Volumes/Vol2/4/2-4.pdf $>$

Hoem, J.M. 1993a. Classical demographic methods of analysis and modern event-history techniques. Pp. 281-291 in IUSSP: $22^{\text {nd }}$ International Population Conference, Montreal, Canada, Vol 3. 
Hoem, J.M. 1993b. Public policy as a fuel of fertility: Effects of a policy reform on the pace of childbearing in Sweden in the 1980s. Acta Sociologica 36: 19-31.

Ilmakunnas, S. 1994. Perhetuki ja syntyvyys (Family support and fertility). Sosiaali- ja terveysministeriön julkaisuja 10. Helsinki: STM.

Ilmakunnas, S. 1997. Public policy and childcare choice. In: Economics of the family and family policies, edited by I. Persson and C. Young. London: Routledge.

Knudsen, L.B. 1999. Recent fertility trends in Denmark - a discussion of the impact of family policy in a period with increasing fertility. Research Reports 11. Odense: the Danish Center for Demographic Research. Available at

$<$ http://www.ou.dk/tvf/DemCenter/Reports.html

Kohler, H-P. and D. Philipov. 2001. Variance effects in the Bongaarts-Feeney Formula. Demography 38 (1): 1-16.

Kohler, H-P. and J.A. Ortega. 2001. Period parity progression measures with continued fertility postponement: a new look at the implications of delayed childbearing for cohort fertility. MPIDR Working Paper WP-2001-01 [online], available at $<$ http://www.demogr.mpg.de/Papers/Working/wp-2001-001.pdf $>$

Korpinen, J. 1997. Lasten kotihoidon tuki ja sen muutokset 1990-luvulla (Children's home care allowance and how it has changed in the 1990s). Helsinki: KELA.

Kravdal, Ø. 1994. The importance of economic activity, economic potential and economic resources for the timing of first births in Norway. Population Studies 48: 249-267.

Lesthaeghe, R. 1995. The second demographic transition in western countries: An interpretation. In: Gender and family change in industrialized countries, edited by K.O. Mason and A-M. Jensen, pp. 17-62. Oxford: Clarendon.

Muuri, A. and L. Vihma. 1991. Kuinka siinä kävikään? Lasten päivähoito ja kotihoidon tuki vuoden 1990 alussa. (How did it turn out? Day care of children and the home care allowance at the beginning of 1990). Raportteja 15/1991. Helsinki: Sosiaali- ja terveyshallitus (National Agency for Welfare and Health).

Nikander, T. 1992. The woman's life course and the family formation. SVT. Population 1992:1. Helsinki: Statistics Finland.

Notkola, I-L. 1994. Hedelmällisyys (Fertility). Pp 64-106 in Koskinen S, Martelin T, Notkola I-L, Notkola V, Pitkänen K (eds.), Suomen väestö The Population of Finland. Helsinki: Gaudeamus.

Notkola, I-L. 1995. Cohort fertility changes and period fertility in 1960-1990 in Finland. Yearbook of Population Research in Finland 32 (1994-1995): 19-31.

Park, C.B. 1976. Lifetime probability of additional births by age and parity for American women, 1935-1968: A new measurement of period fertility. Demography 13 (1): 1-17.

Rallu, J-L. and L. Toulemon. 1994. Period fertility measures: The construction of different indices and their application to France, 1946-89. Population: An English Selection 6: 59-93.

Rønsen, M. 1998. Fertility and public policies - evidence from Norway and Finland. Documents 98/12. Oslo: Statistics Norway.

Sipilä, J. 1995. The right to choose: Day care for children or money for parents. In: Social Policy Review 6, edited by R. Page and J. Baldock, pp.151-169. Canterbury: Social policy Association.

Sipilä, J. and J. Korpinen. 1998. Cash versus child care services in Finland. Social Policy \& Administration 1998; 32 (3): 263-277.

Social Insurance Institution 2000. Statistical Yearbook of the Social Insurance Institution, 1999. Helsinki: KELA.

Statistics Finland 2000. Vital Statistics 1999. Population 2000:13. Helsinki: Statistics Finland. 
Statistics Finland 2001. Statistics online [cited 24 Aug 2001] $<$ http://tilastokeskus.fi/tk/tp/tasku/taskus tyol2.xls $>$

Takala, P. 2000. Lastenhoito ja sen julkinen tuki (Childcare and its public support). STAKES Research Reports 110. Helsinki: STAKES, KELA.

Wennemo, I. 1994. Sharing the costs of children: studies on the development of family support in the OECD countries. Swedish Institute for Social Research 25. Stockholm: Swedish Institute for Social Research. 


\section{Appendix}

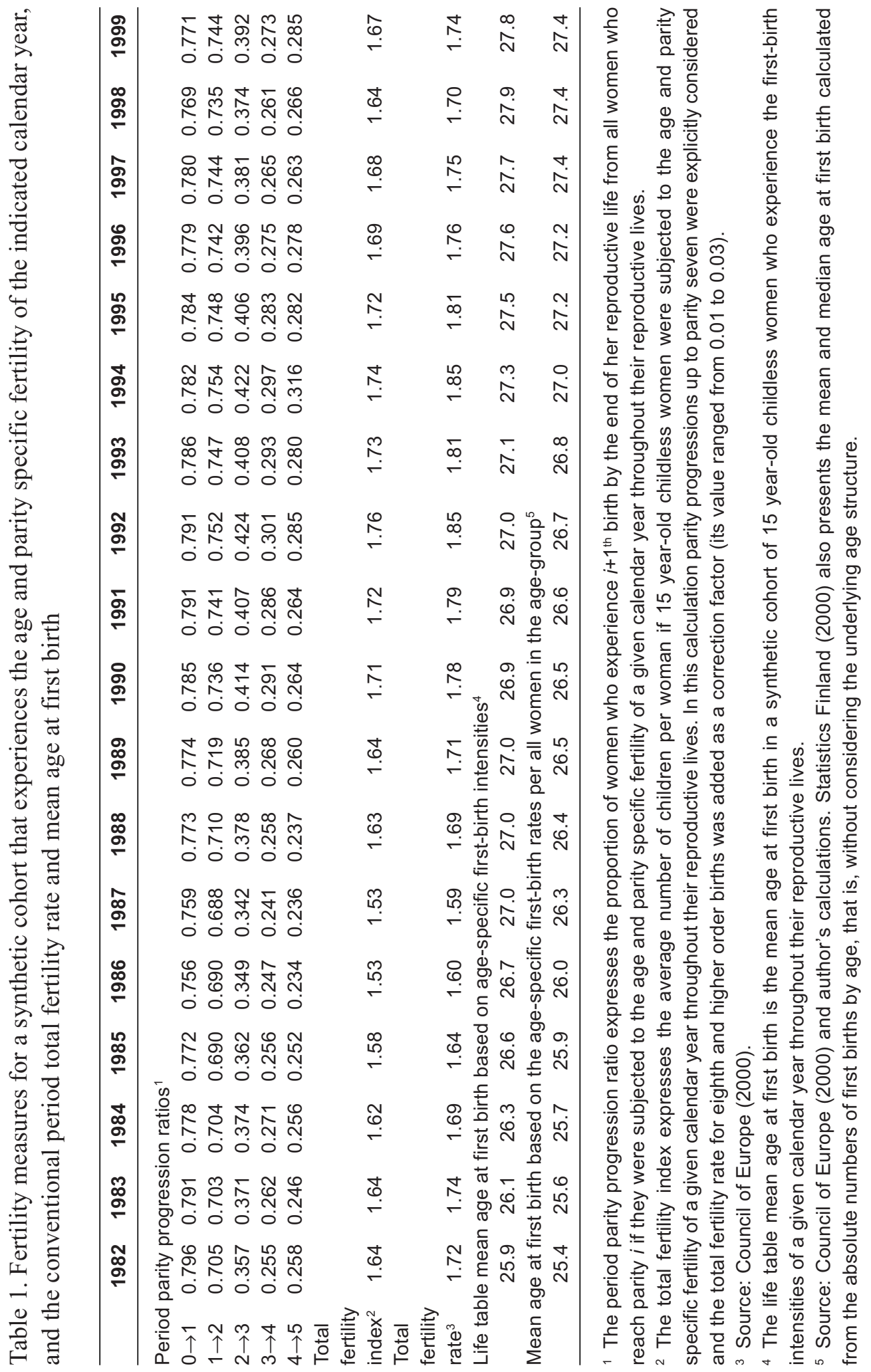

